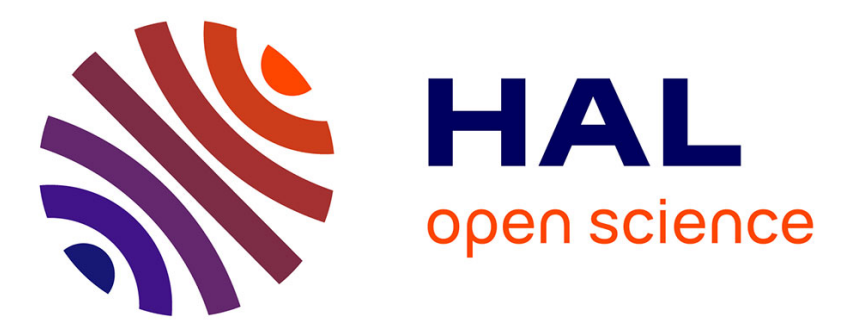

\title{
Long-term impact of secondary preventive treatments in patients with stable angina
}

\author{
Zoltán Vokó, Sophie Brouwer, Jacobus Lubsen, Nicolas Danchin, Jan-Erik \\ Otterstad, Peter H. J. M. Dunselman, Bridget-Anne Kirwan
}

\section{- To cite this version:}

Zoltán Vokó, Sophie Brouwer, Jacobus Lubsen, Nicolas Danchin, Jan-Erik Otterstad, et al.. Longterm impact of secondary preventive treatments in patients with stable angina. European Journal of Epidemiology, 2011, 26 (5), pp.375-383. 10.1007/s10654-011-9558-5 . hal-00671846

\section{HAL Id: hal-00671846 \\ https://hal.science/hal-00671846}

Submitted on 19 Feb 2012

HAL is a multi-disciplinary open access archive for the deposit and dissemination of scientific research documents, whether they are published or not. The documents may come from teaching and research institutions in France or abroad, or from public or private research centers.
L'archive ouverte pluridisciplinaire HAL, est destinée au dépôt et à la diffusion de documents scientifiques de niveau recherche, publiés ou non, émanant des établissements d'enseignement et de recherche français ou étrangers, des laboratoires publics ou privés. 


\section{Long-term impact of secondary preventive treatments in patients with stable}

angina

Zoltán Vokó ${ }^{1} \mathrm{MD}, \mathrm{PhD}$, Sophie de Brouwer ${ }^{2} \mathrm{PhD}$, Jacobus Lubsen ${ }^{2,6} \mathrm{MD}, \mathrm{PhD}$,

5 Nicolas Danchin ${ }^{3}$ MD, FESC, Jan-Erik Otterstad ${ }^{4}$ MD, FESC, Peter HJM Dunselman ${ }^{5}$ MD, PhD, Bridget-Anne Kirwan² PhD

1 Department of Health Policy \& Health Economics, Institute of Economics, Faculty of Social Sciences, Eötvös Loránd University, Budapest, Hungary

102 SOCAR Research, Nyon, Switzerland

3 Hôpital Européen Georges Pompidou, Paris, France

4 Division of Cardiology, Vestfold Hospital, Toensberg, Norway

5 Amphia Ziekenhuis, Breda, the Netherlands

6 Department of Epidemiology and Biostatistics, Erasmus Medical Centre, Rotterdam, The Netherlands

Correspondence to Zoltán Vokó, MD MSc PhD, Department of Health Policy \& Health Economics, Institute of Economics, Faculty of Social Sciences, Eötvös Loránd University, H-1117 Budapest, Pázmány Péter sétány 1/a, phone: +36 (1) 2090555/6865, fax: +36 (1) 372-2997, e-mail: voko@caesar.elte.hu 


\section{ABSTRACT}

We assessed the independent effects of beta blockers, calcium antagonists, lipidlowering drugs, angiotensin converting enzyme inhibitors (ACEls), angiotensin receptor blockers (ARBs), anti-platelet drugs, vitamin $\mathrm{K}$ antagonists, percutaneous

5 coronary intervention $(\mathrm{PCl})$ and coronary artery by-pass grafting (CABG) on mortality and on the composite endpoint of death, myocardial infarction, stroke or heart failure in patients with stable angina pectoris. We estimated the effects of the interventions used at baseline by multivariate Cox regression and during follow-up by G-estimation in 7665 patients followed for a mean of five years in the ACTION trial. Adjusted

10 hazard ratios (95\% confidence intervals) comparing all cause mortality among users during follow-up to non-users were $1.01(0.91,1.09)$ for beta blockade, $0.82(0.75$, $0.89)$ for ACEls or ARBs, $0.93(0.87,0.98)$ for calcium antagonists, $0.54(0.49,0.62)$ for lipid-lowering drugs, $0.49(0.42,0.53)$ for anti-platelet drugs, $0.74(0.69,0.78)$ for $\mathrm{PCl}$, and $0.91(0.82,0.98)$ for CABG. Effects on the composite endpoint were less

15 marked. This observational study confirms that ACEls or ARBs, lipid-lowering and anti-platelet drugs as used in the everyday management of stable angina have independent secondary preventive effects. Calcium antagonists, $\mathrm{PCl}$ and $\mathrm{CABG}$ also appear to improve outcome.

20 Keywords: angina pectoris; cardiovascular agents; coronary artery bypass; coronary disease; percutaneous coronary intervention; secondary prevention, G-estimation 


\section{ABBREVIATIONS}

ACEI angiotensin converting enzyme inhibitor

aHR adjusted hazard ratio

ARB angiotensin receptor blocker

5 ATC Anatomical Therapeutic Chemical

CABG coronary artery by-pass grafting

CEC Critical Events Committee

$\mathrm{Cl} \quad$ confidence interval

GCP good clinical practice

10 GITS gastrointestinal therapeutic system

HF heart failure

HR hazard ratio

$\mathrm{ICH}$ International Conference on Harmonisation

$\mathrm{Ml}$ myocardial infarction

$15 \mathrm{PCl}$ percutaneous coronary intervention 


\section{INTRODUCTION}

Several drug classes, such as anti-platelet agents, beta-blockers, and statins have been shown in clinical trials to reduce morbidity and mortality in patients with coronary heart disease. In the recent CORONA trial, statins surprisingly did not show

5 benefit the sub-group of patients with coronary heart disease and heart failure (HF); this trial demonstrated the need for caution when applying results in a broad population to sub-groups of that population [1]. Few large and long-term trials or data bases exist that allow the evaluation of preventive therapy in the sub-group of patients with coronary heart disease and angina pectoris. However, the ACTION trial was one such trial [2]; the primary purpose of ACTION was to assess the effects of nifedipine GITS in patients with stable symptomatic angina over a mean follow-up of five years [2, 3]. Patients were randomly assigned to treatment with nifedipine GITS or placebo in addition to the other medications prescribed as clinically indicated. In this paper we describe the pattern of prescribed medications, as recommended in guidelines for patients with established coronary heart disease and the effects on mortality and major cardiovascular events of these cardiovascular medications and coronary interventions [4-6]. We adjusted for prognostic factors and considered both the relationship between outcome and treatment at baseline, and treatment during follow-up.

\section{METHODS}

The ACTION trial was carried out in accordance with the Declaration of Helsinki and ICH guidelines for good clinical practice (GCP). To protect patient safety, predefined interim analyses were performed by an independent safety monitoring committee that 25 had access to the medication code. These did not lead to early termination. ACTION 
was a multinational, randomized, placebo-controlled trial comparing the effects of nifedipine GITS versus placebo on clinical outcome in patients aged at least 35 years old with stable symptomatic coronary artery disease who required treatment with anti-anginal drugs [2, 3]. The inclusion criteria were angina pectoris that had been

5 stable for at least one month, and the need for oral or transdermal treatment either to treat or prevent anginal attacks. Patients had to have a history of myocardial infarction (MI), or angiographically proven coronary artery disease, or a positive exercise test or perfusion defect. Major exclusion criteria included left ventricular ejection fraction below $40 \%$ and clinically significant symptoms or signs of HF.

10 Nifedipine GITS (target dose $60 \mathrm{mg}$ once daily) or matching placebo was added to the conventional anti-anginal medication regimen. Physicians were encouraged to optimise risk factor modification and to treat symptomatic angina with appropriate additional medications. Standard baseline assessments included echocardiography, vital signs, electrocardiography, laboratory tests and a full medical history. Blood

15 pressure was recorded with a standard sphygmomanometer in the sitting position after 5 min of rest. ECG abnormalities were coded locally by the treating physician, using a standard coding form. Baseline coronary angiography was not required but clinically significant lesions identified in those past coronary angiograms that were done were documented as described elsewhere [7]. After randomisation, patients

20 were seen in the out-patient clinic at two weeks, six weeks and six months after randomisation; and from then onwards every six months. Between visits, patients were contacted by telephone.

ACTION was completed as planned [2]. Between November 1996 and December 1998, 7665 patients were started on study medication (3825 nifedipine 25 GITS, 3840 placebo), and are the basis of this report. The mean duration of follow-up 
until death or end of study was the same for both treatments (4.94 years) and followup was $97.3 \%$ complete.

\section{Assessment of clinical events during follow-up}

5 Any untoward experience that occurred during the trial was reported as a (serious) adverse event. This included major diagnostic and intervention procedures. According to procedures and pre-defined criteria described elsewhere [8], the Critical Events Committee (CEC) independently determined the occurrence of acute MI, refractory angina, new overt HF, debilitating stroke, and peripheral revascularisation. Each

10 patient could have several clinical events. The CEC determined the order of occurrence.

For the purpose of the present report, we defined chest pain requiring hospitalisation as any chest pain or worsening angina reported by the investigator for which the patient was hospitalised, and included in the definition refractory angina as determined by the CEC. We defined any stroke as either debilitating stroke determined by the CEC or stroke diagnosed by the investigator.

\section{Statistical analyses}

The treatments considered in this analysis were beta blockers, calcium antagonists

20 (which included double-blind active nifedipine GITS and open-label calcium antagonists given on indication), lipid-lowering drugs, angiotensin converting enzyme (ACE) inhibitors, angiotensin receptor blockers (ARBs), aspirin or other anti-platelet drugs, vitamin $\mathrm{K}$ antagonists, percutaneous coronary intervention (PCl) and coronary artery by-pass grafting (CABG). All treatments prescribed at baseline and during

25 follow-up were documented, including indication, daily dose, route of administration, 
and start and end date of use. We classified concomitant drugs according to the Anatomical Therapeutic Chemical (ATC) classification system (WHO Collaborating Center for Drug Statistics Methodology, 2006). For each patient, we calculated the percentage of follow-up time that (combinations of) the drug classes considered were used, and compared the ACTION treatment arms by $t$-tests.

To estimate the occurrence of death and of the composite of death, Ml, stroke and $\mathrm{HF}$, we determined the rates of these events in two different ways. Considering treatment at baseline only, we took rates as the number of patients with event by treatment at baseline, divided by the total person-time of follow-up 'at risk' of event by

10 treatment at baseline based on 'intention-to-treat', i.e. ignoring treatment changes during follow-up. Considering actual treatment during follow-up, we took rates as the number of patients with event by the treatment actually used at the time of event, divided by the total person-time of follow-up 'at risk' that the treatment concerned was actually used. In the latter rate calculations, each patient could contribute to

15 follow-up time 'at risk' both as a user and as a non-user of a particular class of drug, based on start and stop dates for the treatment concerned.

In rate calculations for $\mathrm{CABG}$ and $\mathrm{PCl}$ respectively, we considered that the patient concerned was treated from the date of the first procedure onwards, and ignored repeat coronary revascularisation procedures.

We estimated the effect of treatments on all cause mortality and on the composite of death, MI, stroke and HF. Firstly, to estimate the effects of the treatments given at baseline (including a history of CABG or PCI) on clinical events, we used multivariate Cox regression to estimate hazard ratios comparing treatment with no treatment adjusted for covariates (aHR) and their 95\% confidence intervals 25 (Cls). Adjustments were made for age, gender, history of MI, HF, stroke, frequency of 
angina (none, occasional, regular, frequent, daily), number of significant lesions on coronary angiogram, smoking, baseline total cholesterol $(\geq 5 \mathrm{mmol} / \mathrm{L}$ or $<5 \mathrm{mmol} / \mathrm{L})$, blood pressure (systolic blood pressure (SBP) $\geq 150 \mathrm{mmHg}$ or diastolic blood pressure $(\mathrm{DBP}) \geq 100 \mathrm{mmHg}$; SBP: $140-149 \mathrm{mmHg}$ and DBP $<100 \mathrm{mmHg}$ or DBP:

$590-99 \mathrm{mmHg} ; \mathrm{SBP}<140 \mathrm{mmHg}$ and $\mathrm{DBP}<90 \mathrm{mmHg}$, diabetes mellitus, left ventricular ejection fraction and serum creatinine.

Secondly, we performed G-estimation to estimate the effect of each treatment prescribed during follow-up as a time-dependent covariate based on start and stop dates for drugs, and for $\mathrm{CABG}$ and $\mathrm{PCl}$, the date when the first procedure was performed, respectively [9]. We used the application stgest (STATA10.1) to perform the analysis [10]. Besides the baseline confounders, we adjusted for blood pressure, angina requiring hospitalisation, and total cholesterol level in a time dependent manner. When death was considered as outcome, additional adjustment was made for MI, HF, and stroke in a time-dependent manner. The parameter estimated by Gestimation is the causal survival time ratio. To estimate hazard ratios, we assumed that survival times followed a Weibull distribution and fitted Weibull regression models with the same covariates as the corresponding models in the G-estimation procedures. We have taken the estimates of the shape parameters from the Weibull models to calculate hazard ratios from the causal survival time ratios [9]. We used application gesttowb (STATA10.1) to perform the analysis [10].

Both in the analyses for treatment at baseline and in the time-dependent analyses for treatment during follow-up, the use of vitamin $\mathrm{K}$ antagonists was adjusted for atrial fibrillation or irregular pulse at baseline and in a time-dependent manner. 
Finally, in G-estimation procedures, we estimated the independent effect of each treatment assessed adjusted for the same covariates as in the previous analysis and for the other treatments.

\section{RESULTS}

\section{Baseline patient profile}

The ACTION trial was completed as planned and 7665 patients were started on study medication [2]. $79 \%$ of patients $(n=6084)$ were male and $46 \%(n=3548)$ were 65 years or older. A history of Ml was present in $51 \%(n=3898)$ and $92 \%(n=7070)$ reported anginal attacks. $7479(98 \%)$ had complete information on all covariates considered in Cox regression analyses and are the basis for the remainder of this report.

\section{Cardiovascular drug use}

15 The prescription pattern of beta blockers, lipid-lowering drugs, ACEIs or ARBs and aspirin or another anti-platelet at baseline is given in Table 1. A vitamin $\mathrm{K}$ antagonist was prescribed at baseline for 305 patients (4\%).

During follow-up, patients assigned nifedipine GITS or placebo were prescribed beta blocking, lipid-lowering drugs and aspirin or other anti-platelet drugs to a similar degree (c.f. Table 1). Patients assigned nifedipine used an ACEI or ARB significantly less frequently than those assigned placebo (mean $27 \%$ as opposed to $33 \%$ of follow-up time, $p<0.001)$. All four drugs were used during a mean of $14 \%$ of follow-up time by patients assigned nifedipine as opposed to $18 \%$ of patients assigned placebo $(\mathrm{p}<0.001)$. 


\section{The impact of cardiovascular drugs use on mortality}

As shown in Table 2, only lipid-lowering drugs and aspirin or other anti-platelet drugs were associated with a significantly (95\% confidence interval of aHR does not cover unity) lower death rate adjusted for other covariates when comparing users with nonusers at baseline (aHR 0.78 and 0.75 respectively). Relative to non-users, the use of vitamin $\mathrm{K}$ antagonists was associated with a significantly increased rate of death (aHR 1.38) in an analysis that was also adjusted for atrial fibrillation or irregular pulse.

Time-dependent analyses comparing use during follow-up with non-use with 10 adjustment for other covariates time-dependently are shown in Tables 2 and 3 in addition to analyses comparing treatments at baseline. When drug use during followup was taken into account in this manner, lipid-lowering drugs, ACEls or ARBs, aspirin or other anti-platelet drugs, and calcium antagonists significantly reduced the rate of death (aHRs $0.54,0.82,0.49$, and 0.93 respectively, c.f. Table 2). Use of

15 vitamin $\mathrm{K}$ increased mortality (aHR $1.19, \mathrm{Cl} 1.02,1.37$, c.f. Table 2).

\section{The impact of cardiovascular drugs use on mortality, MI, stroke or HF}

As shown in Table 3, for the outcome death (all cause), MI, stroke or HF, use of beta blockers at baseline was associated with a significantly increased rate of event (aHR

20 1.15) while lipid-lowering drugs was associated with a significantly reduced rate (aHR 0.84 ), relative to non-users. Vitamin $\mathrm{K}$ antagonists had no effect on this outcome.

Drugs that reduced mortality in the time-dependent covariate also significantly reduced the rate of mortality (all cause), MI, stroke or HF (c.f. Table 3). Lipid lowering drugs had the largest effect (aHR $0.73, \mathrm{Cl} 0.70,0.78$, c.f. Table 3). Vitamin $\mathrm{K}$ antagonists were not significantly associated with the combined outcome. Beta- 
blockers use on the other hand increased the risk of death, MI, stroke or HF (aHR 1.07).

\section{Coronary interventions and outcome}

5 CABG had been performed before inclusion in 1749 (23\%) patients, and was performed during follow-up in a further 584 (10\% of those not having baseline history and included in this analysis). CABG was not associated with the rate of death or the combined rate of death, MI, stroke or HF as a baseline covariate. In the timedependent analysis, it did not reduce the rate of the combined event significantly, but

10 it reduced mortality by $9 \%$ (c.f. Tables 2 and 3 ).

PCI had been performed before inclusion in 1956 (26\%) patients, and was performed during follow-up in a further 455 (8\% of those not having baseline history and included in this analysis). Patients with history of $\mathrm{PCl}$ at baseline had a significantly reduced rate of death (aHR 0.67 ) but no significant reduction of the rate

15 of any death, MI, stroke or HF (c.f. Tables 2 and 3). PCl as a time-dependent covariate significantly reduced the rate of death (aHR 0.74$)$ and the rate of any death, MI, stroke or HF (aHR 0.92).

\section{Combined effect of cardiovascular treatments}

20 The conditionally independent effects of cardiovascular treatments during follow-up adjusted for relevant covariates at baseline and time-dependently are shown in Table 4. Use of an ACEI or ARB, calcium antagonist, lipid-lowering drugs, aspirin or another anti-platelet drug, and Vitamin $\mathrm{K}$ antagonist had significant conditionally independent preventive effect both on mortality and on any death, MI, stroke or HF.

25 The rate of death and of the combined outcome of any death, MI, stroke or HF was 
higher in those on a beta-blocker but for death alone, this was not statistically significantly.

CABG had a statistically significant independent effect on mortality (aHR 0.84) but did not have an independent effect on the combined outcome. PCI was

5 associated with a significant reduction of mortality and any death, MI, stroke or HF.

\section{DISCUSSION}

The selection criteria of the ACTION study allowed for the inclusion of a broad spectrum of patients with symptomatic stable angina requiring anti-anginal treatment

10 and who did not have clinical signs of heart failure. Hence the present population is likely to be representative of stable angina patients seen in everyday clinical practice. Patients included in ACTION were slightly older and more often male than patients investigated in two recent large cohorts managed in general practice [11, 12].

The main finding of the present analyses is that three of the four therapies

15 currently recommended for secondary prevention in patients with coronary heart disease, i.e. lipid-lowering drugs, ACEls or ARBs and anti-platelet drugs all improve outcome $[6,13]$. These treatments significantly reduced mortality and the rate of any death, MI, stroke or HF in adjusted time-dependent analyses that took drug use during follow-up into account. Only lipid-lowering and anti-platelet drugs significantly

20 reduced mortality and only lipid lowering drugs reduced the rate of any death, $\mathrm{Ml}$, stroke or $\mathrm{HF}$ when comparing treatment at baseline with no treatment. We attribute this to dilution caused by treatment changes during follow-up and our results underline the importance of taking such changes into account by time-dependent analyses. In time-dependent analysis of actual drug use, adjustment for previous

25 health status is needed, because these are related to the indication of treatments. On 
the other hand, adjustment for future health status should be avoided because they are intermediates in the causal pathways (i.e. they predict the outcome).

Conventional multivariate regression methods (like Cox-regression) are not, but Gestimation procedure is a suitable method to achieve this [9].

Lipid-lowering drugs, ACEls or ARBs and anti-platelet drugs have all been shown to be effective in a broad spectrum of patients with coronary heart disease, or with risk factors for its development [13]. In addition, the present results confirm that secondary preventive agents have conditionally independent effects.

In a cohort of 3031 patients studied between 2002 and 2003, Daly et al. found

10 that beta blockade, statins and anti-platelet therapy were prescribed as monotherapy, dual or triple therapy in $18 \%, 36 \%$ and $35 \%$ of patients respectively [14]. In the present study (Table 1), we found that the proportion of patients prescribed these therapies as mono, dual and triple therapy were $11 \%(n=814), 38 \%(n=2910)$ and $50 \%(n=3853)$ respectively so patients were treated as intensively with triple therapy

15 as patients discharged after acute MI in a French registry [15]. When the present study was performed (between 1996 to 2003), beta blockers were prescribed more frequently than ACEls or ARBs, drug classes not then considered as components of combination therapy [15]. Indeed, $64 \%$ of patients were prescribed a beta blocker and $42 \%$ an ACEI in the Daly et al. cohort as opposed to $80 \%$ and $23 \%$ respectively

20 in this cohort (c.f. Table 1) [14]. In the most recent guidelines for secondary prevention it is recommended to consider the use of ACEls in all patients and ARBs in patients who are ACEl intolerant $[6,13]$.

The only randomised comparison in the ACTION trial was between nifedipine GITS and placebo. To remove confounding when assessing effects of non-

25 randomised treatments as much as possible, we used G-estimation to adjust for 
time-varying confounders. However, confounding by indication can never be absolutely controlled for in non-randomised comparisons [16]. Adjusted comparisons for non-randomised treatments cannot replace appropriately designed randomised trials. Nonetheless, we believe that adjusted analyses of observational data are

5 relevant to confirm that effects predicted based on results of trials can be achieved in clinical practice.

Currently, calcium antagonists are not generally recommended for secondary prevention in patients with coronary heart disease although their usefulness in treating anginal symptoms and lowering blood pressure is widely accepted. The

10 ACTION study did not show an effect of nifedipine GITS on mortality or on the combination of death, $\mathrm{Ml}$, stroke or $\mathrm{HF}$ in a conventional intention-to-treat analyses; nifedipine did reduce the incidence of HF, any stroke, the need for coronary angiography and the need for CABG [2]. In our analysis, adjusted time-dependent analyses taking the actual use of a calcium antagonist during follow-up into consideration showed that calcium antagonists (which included active study treatment) reduced both mortality and the combination of death, MI, stroke or HF. We found that patients assigned placebo were more intensively treated with combination therapy including an ACEI or ARB than patients randomly assigned nifedipine GITS. This may explain why the intention-to-treat analysis did not show significant effects of

20 nifedipine on mortality and the composite endpoint while time-dependent analyses did. Intention-to-treat comparisons are unbiased if there is no effect, but may be diluted when the drug considered has effects relative to placebo on changes made to study or other medications for clinical reasons during follow-up. Furthermore, it needs to be emphasised that this analysis compared the rate of events in patients who actually were using any calcium antagonist (which might have been active double 
blind drug or an open-label calcium antagonist) with the rate of events in patients who were not using a calcium antagonist adjusted for other determinants. Such an analysis is different from comparing the rate of events in patients assigned active treatment with the rate of events in patients assigned placebo, and then disregarding

5 whether the assigned drug was really used during a mean follow-up of almost five years.

Vitamin $\mathrm{K}$ antagonists increased mortality even in the time-dependent analysis. However, when its use was adjusted for the use of other drugs, it significantly reduced both mortality and the rate of any death, MI, stroke or HF. The WARIS II trial concluded that warfarin in combination with aspirin was superior to aspirin alone in reducing the incidence of death, non-fatal reinfarction or thromboembolic cerebral stroke, but was associated with a higher risk of bleeding [17]. Our results may reflect the independent benefit of Vitamin $\mathrm{K}$ antagonists.

Both $\mathrm{CABG}$ and $\mathrm{PCl}$ had a large positive effect on survival. PCI significantly

15 reduced the rate of any death, $\mathrm{Ml}$, stroke or $\mathrm{HF}$, too. These results came as a surprise as we are not aware of any randomised trial that has shown unequivocally that these procedures improve outcome. Recently, the 5-year results of the Clinical Outcomes Utilizing Revascularization and Aggressive Drug Evaluation (COURAGE) trial were reported [18]. In this largest and most contemporary trial addressing the 20 benefit of $\mathrm{PCl}$ in addition to optimal medical therapy in patients with stable coronary artery disease, there were no significant differences in mortality, MI, and stroke between patients with and without $\mathrm{PCl}$. The only difference was that patients initially on medical therapy alone subsequently had more frequently a revascularisation procedure (33\% vs. $21 \%$ ). Patients randomised in the COURAGE trial [18], however, 25 represented only a very small proportion of those screened for eligibility $(6.4 \%)$, 
raising the question of the relevance of the conclusions of the trial in the real world setting. Comparing outcomes between patients with and without $\mathrm{PCl}$ by a timedependent analysis in the present cohort may be biased because it involves events immediately after the procedure only in a minority of patients. Of all patients in the

5 time-dependent analysis who had $\mathrm{PCl}, 1956$ had a history of this procedure performed at least three months before inclusion while 455 had PCl during follow-up. In addition, residual confounding by indication may be present after adjustment.

\section{CONCLUSION}

10 As far as we are aware, this is the first time that such an analysis has been performed to investigate the effectiveness of secondary preventive therapies as actually used in patients with a cardiovascular disease, on outcome. The ACTION trial enabled this analyses to be performed because of the detailed data collected during follow-up for each patient. In summary, this study confirms that ACEls or

15 ARBs, lipid-lowering and anti-platelet drugs as used in the everyday management of patients with stable angina have the secondary preventive effects claimed based on clinical trials. Calcium antagonists $\mathrm{PCI}$, and to a smaller extent $\mathrm{CABG}$ although not proven in clinical trials, also seem to improve outcome in time-dependent nonexperimental comparisons.

\section{ACKNOWLEDGEMENTS}

The contribution of investigators, committee members and other study personnel as listed elsewhere is gratefully acknowledged [2], as is the support of Bayer Healthcare AG. Bayer Healthcare AG had no role in the design and conduct of the study; or in the preparation, review and approval of this manuscript. 


\section{FINANCIAL DISCLOSURE STATEMENT}

The ACTION trial was funded by Bayer Healthcare AG. S de Brouwer, B-A Kirwan, and J Lubsen were full-time employees of SOCAR Research SA, which managed the

5 study. Z Vokó worked as consultant epidemiologist for SOCAR Research SA. PHJM Dunselman was member of the Critical Events Committee and Nicolas Danchin was Chairman of this committee. JE Otterstad was member of the Steering Committee and one of the country coordinators. Members of committees were funded by SOCAR Research SA to attend meetings related to the trial. Z Vokó, N Danchin, JE

10 Otterstad, PHJM Dunselman, J Lubsen have served as consultants to or received travel expenses, or funding for research from other pharmaceutical companies. 


\section{REFERENCES}

1. Kjekshus J, Apetrei E, Barrios V, Böhm M, Cleland JG, Cornel JH, Dunselman P, Fonseca C, Goudev A, Grande P, Gullestad L, Hjalmarson A, Hradec J, Jánosi A, Kamenský G, Komajda M, Korewicki J, Kuusi T, Mach F, Mareev V, McMurray JJ, Ranjith N, Schaufelberger M, Vanhaecke J, van Veldhuisen DJ, Waagstein F, Wedel H, Wikstrand J; CORONA Group. Rosuvastatin in older patients with systolic heart failure. N Engl J Med 2007;357:2248-61.

2. Poole-Wilson PA, Lubsen J, Kirwan BA, van Dalen FJ, Wagener G, Danchin N, Just H, Fox KA, Pocock SJ, Clayton TC, Motro M, Parker JD, Bourassa MG, Dart AM, Hildebrandt P, Hjalmarson A, Kragten JA, Molhoek GP, Otterstad JE, Seabra-Gomes R, Soler-Soler J, Weber S; Coronary disease Trial Investigating Outcome with Nifedipine gastrointestinal therapeutic system investigators. Effect of long-acting nifedipine on mortality and cardiovascular morbidity in patients with stable angina requiring treatment (ACTION trial): randomised controlled trial. Lancet 2004;364:849-57.

3. Lubsen J, Poole-Wilson PA, Pocock SJ, van Dalen FJ, Baumann J, Kirwan BA, Parker AB. Design and current status of ACTION: A Coronary disease Trial Investigating Outcome with Nifedipine GITS. Gastro-Intestinal Therapeutic System. Eur Heart J 1998;19 Suppl I:I20-I32.

20 4. Management of stable angina pectoris. Recommendations of the Task Force of the European Society of Cardiology. Eur Heart J 1997 Mar;18(3):394-413.

5. Dalal H, Evans PH, Campbell JL. Recent developments in secondary prevention and cardiac rehabilitation after acute myocardial infarction. Br Med J 2004;328:693-7. 
6. Fox K, Garcia MA, Ardissino D, Buszman P, Camici PG, Crea F, Daly C, De Backer G, Hjemdahl P, Lopez-Sendon J, Marco J, Morais J, Pepper J, Sechtem U, Simoons M, Thygesen K, Priori SG, Blanc JJ, Budaj A, Camm J, Dean V, Deckers J, Dickstein K, Lekakis J, McGregor K, Metra M, Morais J, Osterspey A, Tamargo J, Zamorano JL; Task Force on the Management of Stable Angina Pectoris of the European Society of Cardiology; ESC Committee for Practice Guidelines (CPG). Guidelines on the management of stable angina pectoris: executive summary: the Task Force on the Management of Stable Angina Pectoris of the European Society of Cardiology. Eur Heart J 2006;27:1341-81.

10 7. Kirwan BA, Lubsen J, Poole-Wilson PA. Treatment of angina pectoris: associations with symptom severity. Int J Cardiol 2005;98:299-306.

8. Kirwan BA, Lubsen J, Brouwer S, Danchin N, Battler A, Bayes de Luna A, Dunselman PH, Glasser S, Koudstaal PJ, Sutton G, van Dalen FJ, Poole-Wilson PA; ACTION (A Coronary disease Trial Investigating Outcome with Nifedipine GITS) investigators. Diagnostic criteria and adjudication process both determine published event-rates: The ACTION trial experience. Contemp Clin Trials 2007;28:720-9.

9. Mark SD, Robins JM. Estimating the causal effect of smoking cessation in the presence of confounding factors using a rank preserving structural failure time model. Stat Med 1993;12:1605-28.

10. Sterne JAC, Tilling K. G-estimation of causal effects, allowing for time-varying confounding. Stata J 2002;2:164-82. 
11. Filippi A, Gensini G, Bignanimi AA, Sabatini A, Mazzaglia G, Cricelli C. Management of patients with suspected angina, but without known myocardial infarction: a cross-sectional survey. Br J Gen Pract 2004;54:429-33.

12. Hemingway $H$, McCallum A, Shipley M, Manderbacka K, Martikainen $P$, Keskimaki I. Incidence and prognostic implications of stable angina pectoris among women and men. JAMA 2006;295:1404-11.

13. Gibbons RJ, Abrams J, Chatterjee K, Daley J, Deedwania PC, Douglas JS, Ferguson TB Jr, Finn SD, Fraker TD Jr, Gardin JM, O'Rourke RA, Pasternak RC, Williams SV; American College of Cardiology; American Heart Association Task Force on practice guidelines (Committee on the Management of Patients With Chronic Stable Angina). ACC/AHA 2002 guideline update for the management of patients with chronic stable angina--summary article: a report of the American College of Cardiology/American Heart Association Task Force on practice guidelines (Committee on the Management of Patients With Chronic Stable Angina). J Am Coll Cardiol 2003;41:159-68.

14. Daly C, Clemens F, Lopez-Sendon JL, Tavazzi L, Boersma E, Danchin N, Delahaye F, Gitt A, Julian D, Mulcahy D, Ruzyllo W, Thygesen K, Verheugt F, Fox KM; Euro Heart Survey Investigators. The impact of guideline compliant medical therapy on clinical outcome in patients with stable angina: findings from the Euro Heart Survey of stable angina. Eur Heart J 2006;27:1298-304.

15. Danchin N, Cambou JP, Hanania G, Kadri Z, Genes N, Lablanche JM, Blanchard D, Vaur L, Clerson P, Guéret P; USIC 2000 investigators. Impact of combined secondary prevention therapy after myocardial infarction: data from a nationwide French registry. Am Heart J 2005;150:1147-53. 
16. Miettinen OS. The need for randomization in the study of intended effects. Stat Med 1983;2:267-71.

17. Hurlen M, Abdelnoor M, Smith P, Erikssen J, Arnesen H. Warfarin, aspirin, or both after myocardial infarction. N Engl J Med 2002;347:969-74.

5 18. Boden WE, O'Rourke RA, Teo KK, Hartigan PM, Maron DJ, Kostuk WJ, et al. Optimal medical therapy with or without PCl for stable coronary disease. N Engl J Med 2007;356:1503-16. 
Table 1. Use of (combinations of) secondary preventive treatments at baseline and during follow-up in 7665 patients with stable angina

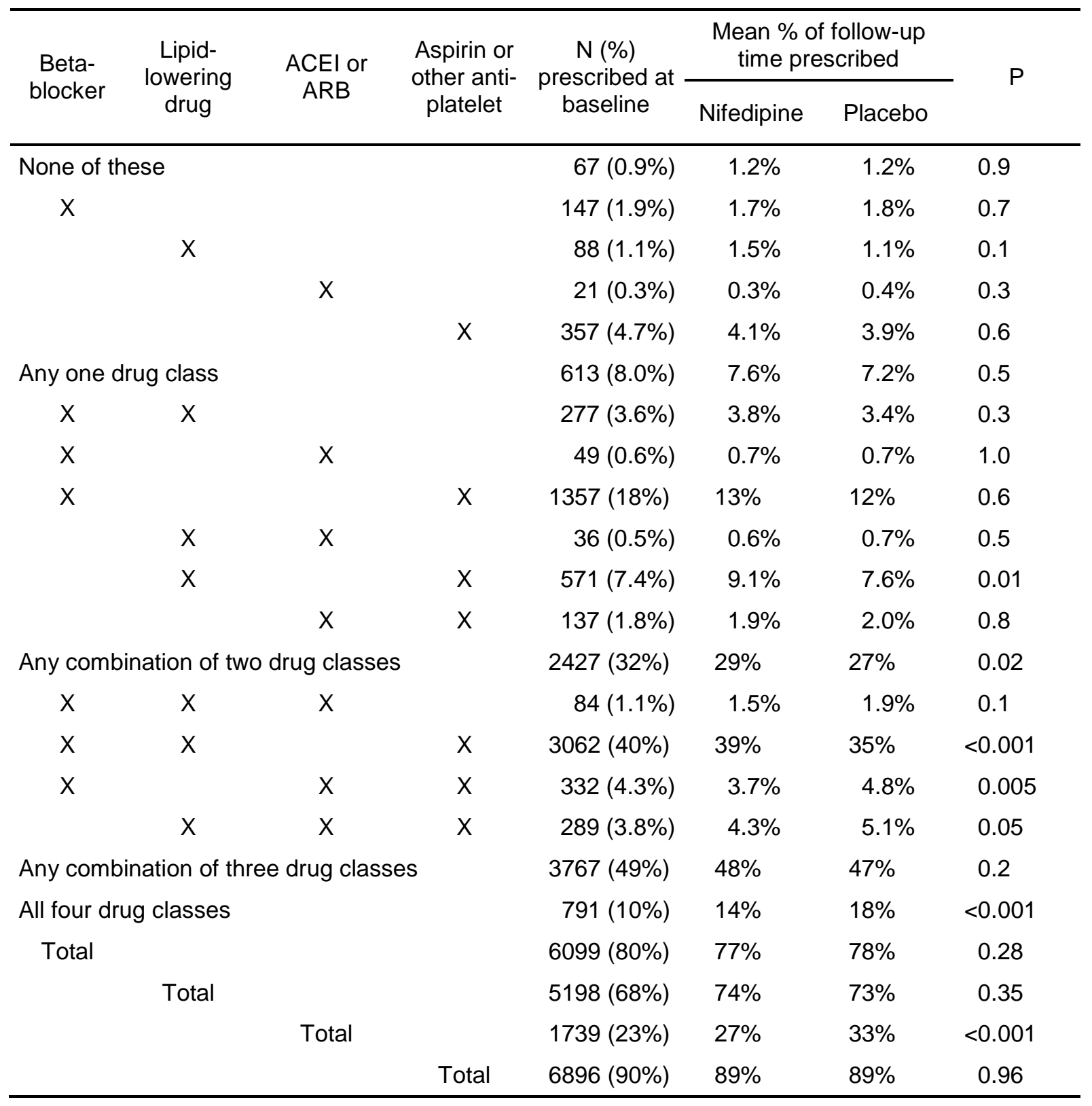

$\mathrm{ACEl}$, angiotensin-converting enzyme inhibitor; $\mathrm{ARB}$, angiotensin receptor blocker 
Table 2. Cardiovascular therapy and death

\begin{tabular}{|c|c|c|c|c|c|c|c|}
\hline & \multicolumn{3}{|c|}{$\begin{array}{l}\text { Comparing treatment with no treatment } \\
\text { at baseline }\end{array}$} & \multicolumn{4}{|c|}{$\begin{array}{l}\text { Comparing treatment with no treatment } \\
\text { during follow-up }\end{array}$} \\
\hline & $\begin{array}{l}\text { Treatment } \\
\text { at baseline }\end{array}$ & $\begin{array}{l}\text { No. of deaths } \\
\text { (rate/100 pyrs) }\end{array}$ & $\begin{array}{l}\text { Adjusted }{ }^{*} \mathrm{HR} \\
(95 \% \mathrm{Cl})\end{array}$ & $\begin{array}{l}\% \text { of total } \\
\text { f-up used }\end{array}$ & $\begin{array}{l}\text { No. of deaths } \\
\text { (rate/100 pyrs) }\end{array}$ & $\begin{array}{l}\text { Survival time } \\
\text { ratio† }(95 \% \mathrm{Cl})\end{array}$ & $\begin{array}{l}\text { Adjusted† HR } \\
(95 \% \mathrm{Cl})\end{array}$ \\
\hline \multicolumn{8}{|c|}{ Beta-blocker } \\
\hline Yes & $5950(80 \%)$ & $463(1.57)$ & $1.07(0.87,1.30)$ & 77.7 & 377 (1.31) & $0.99(0.93,1.08)$ & $1.01(0.91,1.09)$ \\
\hline No & $1529(20 \%)$ & $124(1.66)$ & ref. cat. & & $210(2.55)$ & ref. cat. & ref. cat. \\
\hline \multicolumn{8}{|c|}{ Lipid-lowering drug } \\
\hline Yes & $5074(68 \%)$ & $342(1.35)$ & $0.78(0.66,0.92)$ & 74.5 & $274(1.00)$ & $1.60(1.45,1.72)$ & $0.54(0.49,0.62)$ \\
\hline No & 2405 (32\%) & $245(2.11)$ & ref. cat. & & $313(3.32)$ & & ref. cat. \\
\hline \multicolumn{8}{|c|}{ ACEI or ARB: } \\
\hline Yes & $1694(23 \%)$ & $142(1.73)$ & $0.99(0.81,1.20)$ & 30.1 & $176(1.58)$ & $1.17(1.09,1.25)$ & $0.82(0.75,0.89)$ \\
\hline No & 5785 (77\%) & $445(1.55)$ & ref. cat. & & $411(1.59)$ & ref. cat. & ref. cat. \\
\hline \multicolumn{8}{|c|}{$\begin{array}{l}\text { Aspirin } \\
\text { or other anti-platelet: }\end{array}$} \\
\hline Yes & $6715(90 \%)$ & 495 (1.49) & $0.75(0.60,0.94)$ & 89.2 & $378(1.15)$ & $1.76(1.67,1.98)$ & $0.49(0.42, .0 .53)$ \\
\hline No & $764(10 \%)$ & $92(2.51)$ & ref. cat. & & $209(5.23)$ & ref. cat. & ref. cat. \\
\hline \multicolumn{8}{|c|}{ Vitamin $\mathrm{K}$ antagonist: } \\
\hline Yes & $294(4 \%)$ & $45(3.15)$ & $1.38(1.00,1.90)^{\ddagger}$ & 5.4 & $73(3.66)$ & $0.87(0.77,0.99)^{\ddagger}$ & $1.19(1.02,1.37)^{\ddagger}$ \\
\hline No & 7185 (96\%) & $542(1.53)$ & ref. cat. & & $514(1.47)$ & ref. cat. & ref. cat. \\
\hline \multicolumn{8}{|c|}{ Calcium antagonist: } \\
\hline Yes & $3740(50 \%)$ & 305 (1.65) & $1.09(0.93,1.28)$ & 44.8 & $163(0.98)$ & $1.06(1.02,1.12)$ & $0.93(0.87,0.98)$ \\
\hline No & $3739(50 \%)$ & $282(1.53)$ & ref. cat. & & $424(2.08)$ & ref. cat. & ref. cat. \\
\hline
\end{tabular}




\begin{tabular}{|c|c|c|c|c|c|c|c|}
\hline & \multicolumn{3}{|c|}{$\begin{array}{l}\text { Comparing treatment with no treatment } \\
\text { at baseline }\end{array}$} & \multicolumn{4}{|c|}{$\begin{array}{l}\text { Comparing treatment with no treatment } \\
\text { during follow-up }\end{array}$} \\
\hline & $\begin{array}{l}\text { Treatment } \\
\text { at baseline }\end{array}$ & $\begin{array}{l}\text { No. of deaths } \\
\text { (rate/100 pyrs) }\end{array}$ & $\begin{array}{l}\text { Adjusted }{ }^{*} \mathrm{HR} \\
(95 \% \mathrm{Cl})\end{array}$ & $\begin{array}{l}\% \text { of total } \\
\text { f-up used }\end{array}$ & $\begin{array}{l}\text { No. of deaths } \\
\text { (rate/100 pyrs) }\end{array}$ & $\begin{array}{l}\text { Survival time } \\
\text { ratio† }(95 \% \mathrm{Cl})\end{array}$ & $\begin{array}{l}\text { Adjusted }+\mathrm{HR} \\
(95 \% \mathrm{Cl})\end{array}$ \\
\hline \multicolumn{8}{|l|}{ CABG: } \\
\hline Yes & $1749(23 \%)$ & $150(1.72)$ & $1.00(0.78,1.27)$ & 27.6 & $192(1.88)$ & $1.08(1.02,1.18)$ & $0.91(0.82,0.98)$ \\
\hline No & $5730(77 \%)$ & $437(1.55)$ & ref. cat. & & $395(1.48)$ & ref. cat. & ref. cat. \\
\hline \multicolumn{8}{|l|}{ PCl: } \\
\hline Yes & $1956(26 \%)$ & $95(0.97)$ & $0.67(0.52,0.85)$ & 29.6 & $123(1.13)$ & $1.23(1.21,1.34)$ & $0.74(0.69,0.78)$ \\
\hline No & $5523(74 \%)$ & $492(1.81)$ & ref. cat. & & $464(1.78)$ & ref. cat. & ref. cat. \\
\hline
\end{tabular}

pyrs, person years; HR, hazard ratio; Cl, confidence interval; ref. cat., reference category; ACEI, angiotensin-converting enzyme inhibitor; ARB, angiotensin receptor blocker; CABG, coronary artery

bypass grafting; $\mathrm{PCl}$, percutaneous coronary intervention

* $\quad$ Adjusted for age, gender, history of MI, HF and stroke, frequency of angina, number of significant lesions on coronary angiogram, smoking, total cholesterol, blood pressure, diabetes mellitus,

left ventricular ejection fraction, and serum creatinine at baseline.

$\dagger \quad$ Adjusted for age, gender, history of MI, HF and stroke, frequency of angina, number of significant lesions on coronary angiogram, smoking, total cholesterol, blood pressure, diabetes mellitus,

left ventricular ejection fraction, serum creatinine at baseline and for blood pressure, angina requiring hospitalisation, MI, HF, stroke and total cholesterol level in a time dependent manner. Drug

use treated as a time-dependent indicator variable that could change continuously and interventions as a time-dependent indicator variable that could change once at the time of the first

intervention concerned.

$\ddagger \quad$ Adjusted in addition for atrial fibrillation or irregular pulse at baseline and in a time-dependent manner. 
Table 3. Cardiovascular therapy and first occurrence of death, MI, stroke or HF

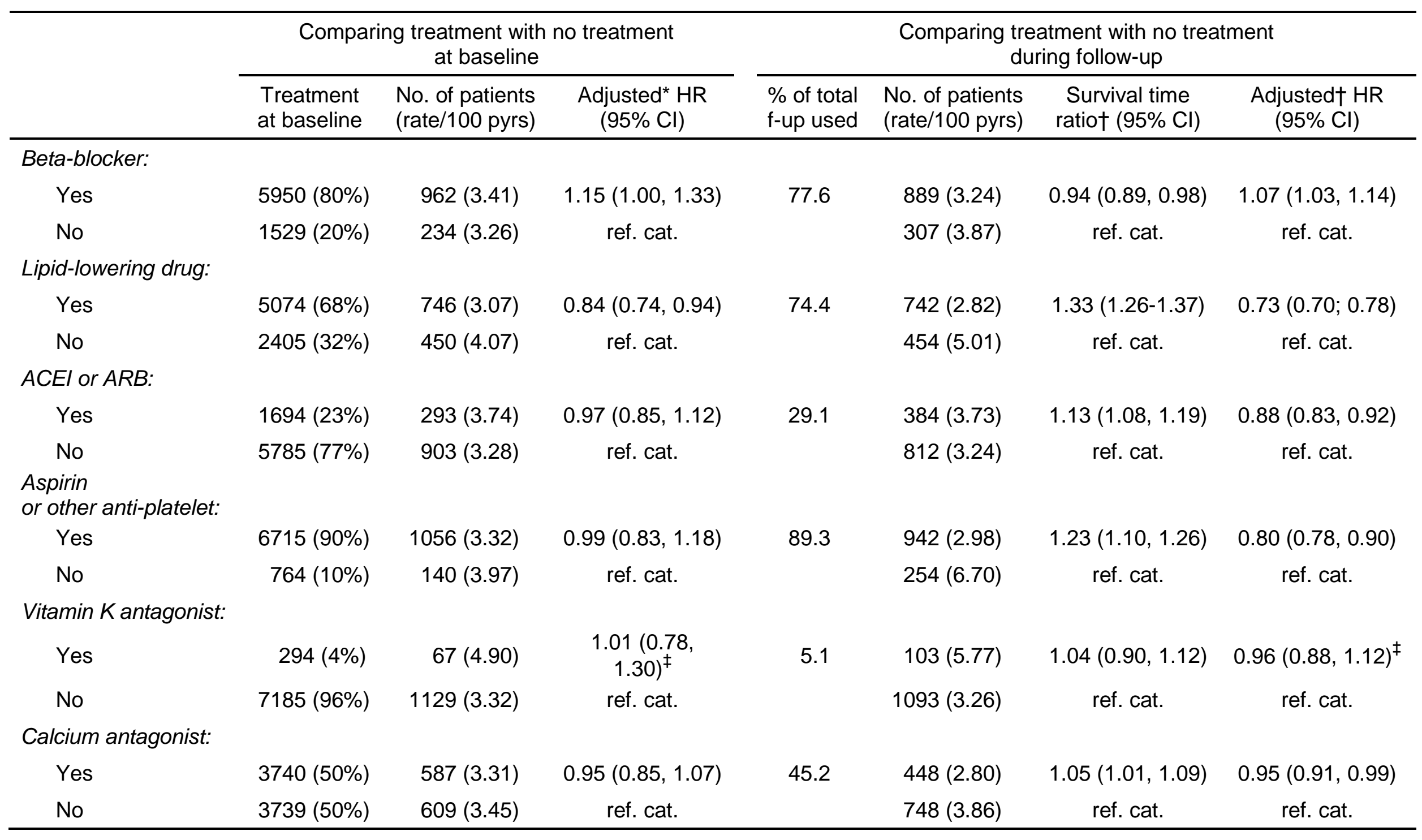




\begin{tabular}{|c|c|c|c|c|c|c|c|}
\hline & \multicolumn{3}{|c|}{$\begin{array}{l}\text { Comparing treatment with no treatment } \\
\text { at baseline }\end{array}$} & \multicolumn{4}{|c|}{$\begin{array}{c}\text { Comparing treatment with no treatment } \\
\text { during follow-up }\end{array}$} \\
\hline & $\begin{array}{l}\text { Treatment } \\
\text { at baseline }\end{array}$ & $\begin{array}{l}\text { No. of patients } \\
\text { (rate/100 pyrs) }\end{array}$ & $\begin{array}{l}\text { Adjusted }{ }^{*} \mathrm{HR} \\
(95 \% \mathrm{Cl})\end{array}$ & $\begin{array}{l}\% \text { of total } \\
\text { f-up used }\end{array}$ & $\begin{array}{l}\text { No. of patients } \\
\text { (rate/100 pyrs) }\end{array}$ & $\begin{array}{l}\text { Survival time } \\
\text { ratio† }(95 \% \mathrm{Cl})\end{array}$ & $\begin{array}{l}\text { Adjusted† HR } \\
\quad(95 \% \mathrm{CI})\end{array}$ \\
\hline Yes & $1749(23 \%)$ & $332(4.01)$ & $1.07(0.90,1.26)$ & 26.8 & $393(4.04)$ & $1.02(0.97,1.05)$ & $0.98(0.95,1.04)$ \\
\hline No & $5730(77 \%)$ & 864 (3.19) & ref. cat. & & $813(3.14)$ & ref. cat. & ref. cat. \\
\hline Yes & $1956(26 \%)$ & $261(2.79)$ & $0.92(0.79,1.07)$ & 29.0 & $300(2.92)$ & $1.08(1.05,1.13)$ & $0.92(0.87,0.95)$ \\
\hline No & 5523 (74\%) & 935 (3.60) & ref. cat. & & 896 (3.57) & ref. cat. & ref. cat. \\
\hline
\end{tabular}

pyrs, person years; HR, hazard ratio; Cl, confidence interval; ref. cat., reference category; ACEI, angiotensin-converting enzyme inhibitor; ARB, angiotensin receptor blocker; CABG, coronary artery

bypass grafting; $\mathrm{PCl}$, percutaneous coronary intervention

* $\quad$ Adjusted for age, gender, history of MI, HF and stroke, frequency of angina, number of significant lesions on coronary angiogram, smoking, total cholesterol, blood pressure, diabetes mellitus,

left ventricular ejection fraction, and serum creatinine at baseline.

Adjusted for age, gender, history of MI, HF and stroke, frequency of angina, number of significant lesions on coronary angiogram, smoking, total cholesterol, blood pressure, diabetes mellitus,

left ventricular ejection fraction, serum creatinine at baseline and for blood pressure, angina requiring hospitalisation and total cholesterol level in a time dependent manner. Drug use treated as

a time-dependent indicator variable that could change continuously and interventions as a time-dependent indicator variable that could change once at the time of the first intervention

concerned.

$\ddagger \quad$ Adjusted in addition for atrial fibrillation or irregular pulse at baseline and in a time-dependent manner. 
Table 4. Conditionally independent effects of cardiovascular treatments during follow-up (time-dependent analysis by G-estimation procedure)

\begin{tabular}{|c|c|c|c|c|}
\hline & \multicolumn{2}{|c|}{ Any death } & \multicolumn{2}{|c|}{ Any death, MI, stroke or HF } \\
\hline & $\begin{array}{l}\text { Causal survival } \\
\text { time ratio }(95 \% \mathrm{Cl})\end{array}$ & $\begin{array}{c}\mathrm{HR} \\
(95 \% \mathrm{Cl})\end{array}$ & $\begin{array}{l}\text { Causal survival time } \\
\text { ratio }(95 \% \mathrm{Cl})\end{array}$ & $\begin{array}{c}\mathrm{HR} \\
(95 \% \mathrm{Cl})\end{array}$ \\
\hline Beta blocker & $0.96(0.89,1.01)$ & $1.06(0.98,1.16)$ & $0.92(0.89,0.96)$ & $1.09(1.05,1.15)$ \\
\hline Lipid-lowering drugs & $1.53(1.42,1.61)$ & $0.58(0.54,0.64)$ & $1.29(1.25,1.36)$ & $0.76(0.71,0.78)$ \\
\hline ACEI or ARB & $1.10(1.00,1.18)$ & $0.89(0.81,1.00)$ & $1.10(1.06,1.17)$ & $0.90(0.84,0.94)$ \\
\hline Aspirin or other anti-platelet & $1.73(1.55,1.99)$ & $0.49(0.41,0.57)$ & $1.12(1.06,1.26)$ & $0.88(0.77,0.94)$ \\
\hline Vitamin $\mathrm{K}$ antagonist & $1.12(1.02,1.37)$ & $0.87(0.67,0.97)$ & $1.12(1.04,1.37)$ & $0.88(0.71,0.96)$ \\
\hline Calcium antagonist & $1.06(1.02,1.12)$ & $0.92(0.87,0.98)$ & $1.05(1.02,1.09)$ & $0.95(0.91,0.98)$ \\
\hline CABG & $1.15(1.04,1.22)$ & $0.84(0.77,0.95)$ & $1.02(0.97,1.06)$ & $0.98(0.94,1.04)$ \\
\hline $\mathrm{PCl}$ & $1.25(1.18,1.31)$ & $0.75(0.71,0.81)$ & $1.08(1.03,1.11)$ & $0.92(0.89,0.97)$ \\
\hline
\end{tabular}

$\mathrm{HR}$, hazard ratio; $\mathrm{Cl}$, confidence interval; $\mathrm{MI}$, myocardial infarction; HF, heart failure; ACEI, angiotensin-converting enzyme inhibitor; ARB, angiotensin receptor blocker; CABG, coronary artery

bypass grafting; $\mathrm{PCl}$, percutaneous coronary intervention

* Adjusted for age, gender, history of MI, HF and stroke, frequency of angina, number of significant lesions on coronary angiogram, smoking, total cholesterol, systolic blood pressure, diabetes

mellitus, left ventricular ejection fraction, serum creatinine at baseline, and for blood pressure, angina requiring hospitalisation, MI, HF, stroke and total cholesterol level in a time dependent

manner. Drug use treated as a time-dependent indicator variable that could change continuously and interventions as a time-dependent indicator variable that could change once at the time of

the first intervention concerned. Adjusted for the use of other drugs and history of interventions at baseline and also in a time-dependent manner. 
$\dagger$ Adjusted in addition for atrial fibrillation or irregular pulse at baseline and in a time-dependent manner. 